\title{
3
}

\section{Implementation of a Unique Real Time Flash Flood Forecasting System in Martinique (France)}

\author{
N. Peyron, M. Raymond, F. Alfonsi and B. Naigre
}

In France and especially in the Caribbean islands, the serious damage caused in urban areas by the recent flash floods showed the importance of efficient and adapted reactions of the municipality. Faced by a flash flood crisis, decisions should be taken based on the current information available that is often very limited due to the lack of time to obtain, manage and analyse them.

Therefore, the Conseil Général of Martinique decided to develop an operational, integrated and innovative tool, SDAC (Système Départemental d'Alerte de Crues), to be able to forecast and manage urban flooding in real time. The modeling system is based on predicted precipitations from rain gauges (radar imaging will be integrated soon), a rainfall-runoff model, a hydraulic model developed for urban areas and a risk definition representing the flood importance.

This innovative system has been initially implemented on four watersheds of the island in 1999, including the Lezarde basin which is particularly vulnerable to floods that induce significant damage on the road system as well as on the economic activities of the island (e.g. airport, commercial centre). In 2005 , the system was significantly improved and innovative steps were taken to reach different objectives: (i) to improve the robustness and precision of the flood forecast; (ii) to improve the alert system for small watersheds; (iii) to represent in details the flooding zones in the urban areas using GIS; (iv) to insure warning messages reception that allow prevention actions; and (v) to make

Peyron, N., M. Raymond, F. Alfonsi and B. Naigre. 2010. "Implementation of a Unique Real Time Flash Flood Forecasting System in Martinique (France)." Journal of Water Management Modeling R236-03. doi: 10.14796/JWMM.R236-03.

(C) CHI 2010 www.chijournal.org ISSN: 2292-6062 (Formerly in Dynamic Modeling of Urban Water Systems. ISBN: 978-0-9808853-3-0) 
the forecasting data and maps available on the internet for public information. The system is currently operational and is very promising since the results show the significant advantages obtained when combining growing computer power with increasing urban hydrological knowledge.

The next step in 2009 is to include the radar data and the sea level data in real time in order to (i) enhance the anticipation of rainfall that can produce flood, and (ii) take into account the sea level hydraulic constraint that could be significant for some basins during a big storm.

\subsection{Context for SDAC}

Frequently, very intense storm events induce catastrophic floods in the Caribbean islands, and especially in Martinique (France). The particular morphology of the island, which is drained by medium to small rivers called ravines that are generally dry, and the urbanization that took place on their downstream parts close to the coasts, creates the combination of flood risk and vulnerability (people, goods, services and the island airport) that contributes to particularly important human and economic risks.

In 1999, the Conseil Général of Martinique, that is in charge of the road network management, decided to take action on the development of a flood warning system, SDAC. This first version of the system was based on a network of rain gauges and river water level recorders located on the island. In this project, various entities are collaborating: Météo France, the state ministries, and the different municipalities.

In 2006, the Conseil Général decided to significantly improve the system through various actions:

- Update the data acquisition process;

- Implement real time hydrological modeling;

- Develop warning and actions procedures in their security plans; and

- Make the forecasted flooding maps available on the internet.

\subsection{The Objectives of SDAC}

The objectives of SDAC are as follows:

- Follow-up and hydrological forecast for the anticipation of the flood events;

- Management of flood alarms and warnings; and

- Management of the security plans. 
This ready-to-use system includes the complete equipment required for the crisis control room (furniture, data-processing equipment, software, communication equipment, automatic calling system, secured power, guarantee and maintenance) as well as in-situ video control.

SDAC was developed by the association between Egis Eau and CS SI. Egis Eau was in charge of the hydrological and hydraulic modeling parts, as well as the risk study and the flooding maps development. The informatics company CS SI was in charge of the informatics part (supply, software development, data processing and SIG tools management).

Four different watersheds, located on each of the sea coasts of the island, are under control by the system (Figure 3.1):

- $\quad$ Lézarde River $\left(132 \mathrm{~km}^{2}\right)$;

- Rivière Pilote $\left(36 \mathrm{~km}^{2}\right)$;

- DesRoses River $\left(22 \mathrm{~km}^{2}\right)$; and

- Carbet River $\left(23 \mathrm{~km}^{2}\right)$.

Around 70000 people are living on the four watersheds that are covered by close to $1000 \mathrm{~km}$ of roads.

\subsection{The Functions of SDAC}

\subsubsection{Data Acquisition}

The data from the 20 rain gauges and 15 water level recorders that are managed by the Conseil Général are collected every $15 \mathrm{~min}$ by phone lines. The time step of the data is $6 \mathrm{~min}$.

The center where the data are collected is in the Conseil Général building in Fort de France (Figure 3.2). A set of video cameras completes the acquisition system by providing real time pictures of the most sensible points of the rivers.

\subsubsection{Hydrological Computations}

Based on the observed rainfall quantities, the system computes flow forecasts at various points of the rivers and especially at the entry of the most urbanized areas. These estimated flow values are produced by rainfall-runoff models that are calibrated based on past observed events. The various behaviours of the rural and urbanized watersheds are represented. The simulations take into account the existing storage basins. The hydrological predicted values are updated 


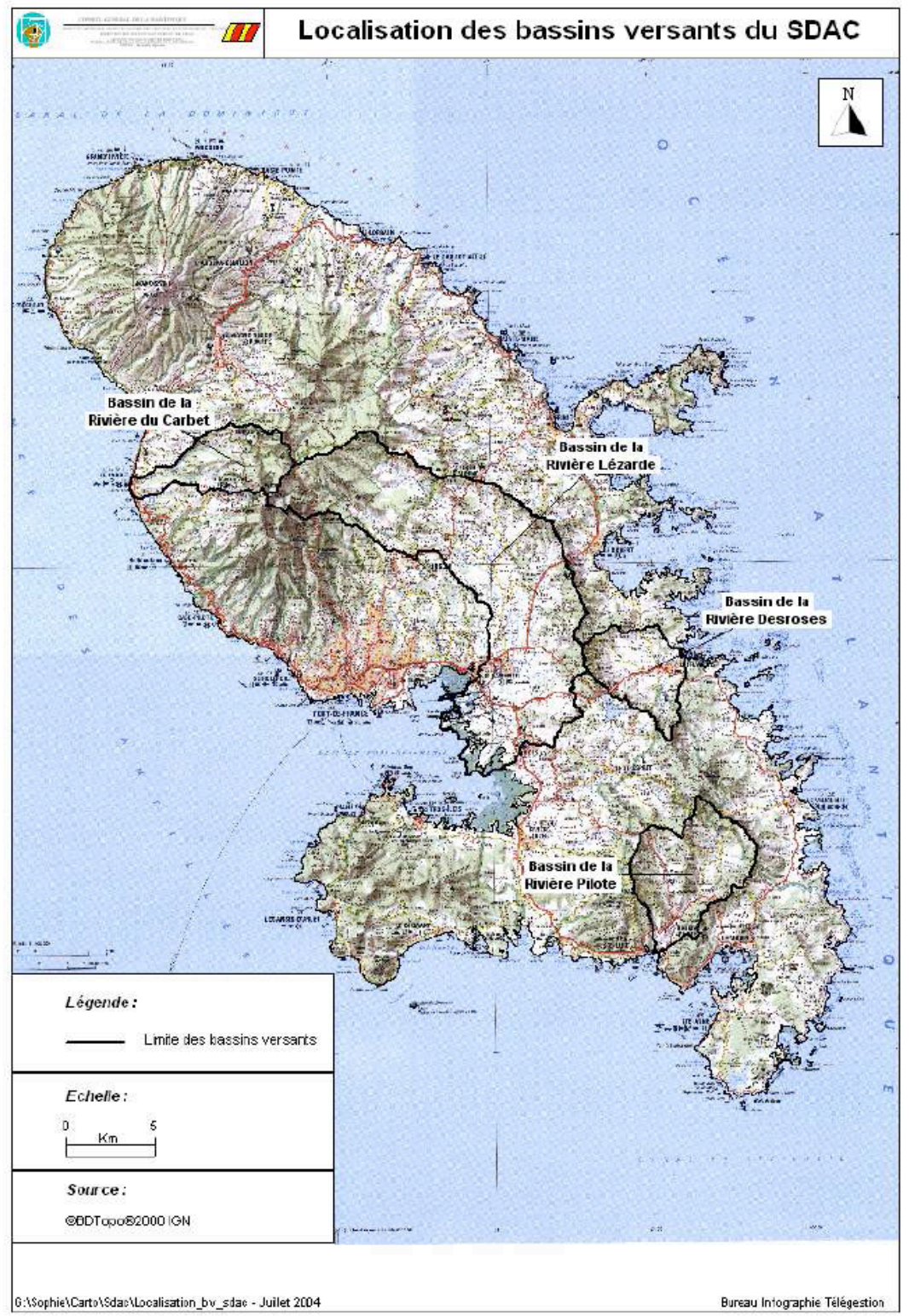

Figure 3.1 The four basins considered by SDAC. 


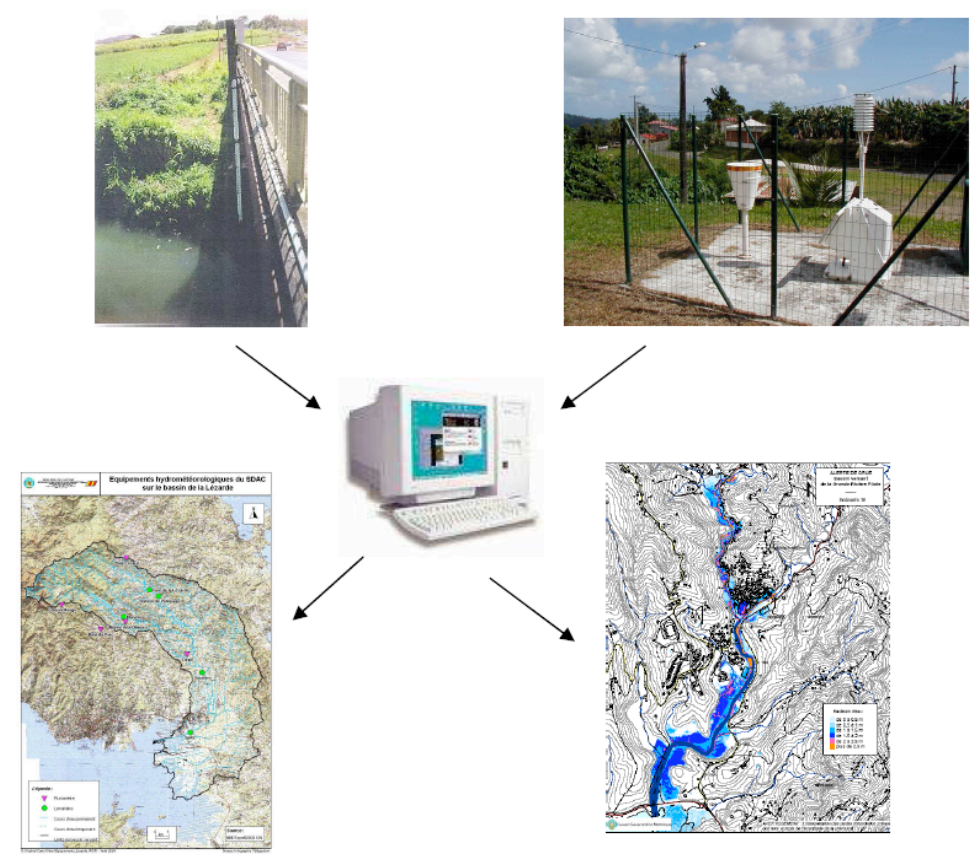

Figure 3.2 Main functionalities of SDAC: data acquisition and maps presentation of the resulting forecasts.

every $15 \mathrm{~min}$. The models used for the real time forecasts are (i) the GR4 model developed by the CEMAGREF for the rural parts (a two linear reservoirs models with four parameters to calibrate [Editjano et Michel, 1989; Perrin, 2000]); and (ii) the RERAM model for the residential areas (the French Desbordes rainfall-runoff model [Chocat, 1997]).

The hydrological calculations are based on a model structure built from a sub-basin delimitation associated with a tree structure network, in which the hydrographs are routed. In real time, the flow values are estimated at the critical overflow points; that is, at the entrance of the vulnerable sectors. These points of overflow which are located just upstream of the urbanized areas, are represented in Figure 3.3. The computation time necessary for a complete cycle of forecasts simulation is around $2 \mathrm{~min}$, which is absolutely compatible with the speed requirements of the system. 


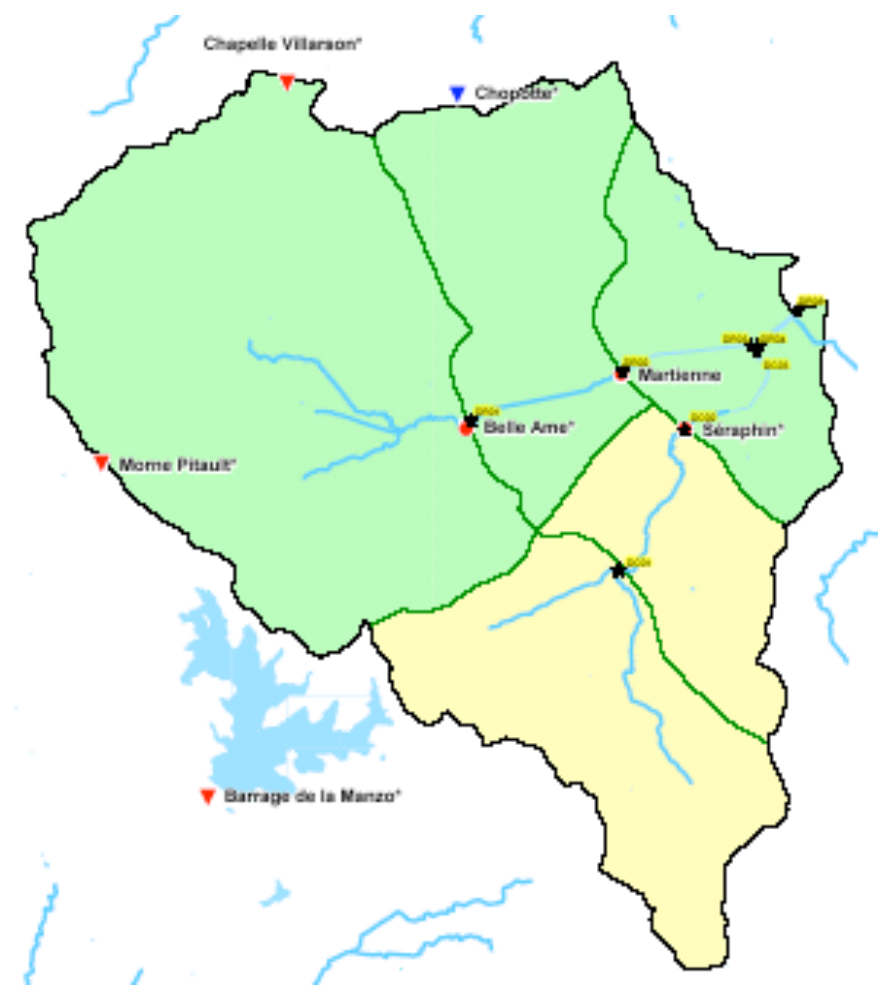

Figure 3.3 Structure of the model with the main computations points for the River Desroses basin.

\subsubsection{Identification of the Most Probable Flood Hazard Scenario}

The reduced capacity of the river channels associated with the important vulnerable sectors in their urbanized part leads to catastrophic overflows in populated areas. Such flows, that are then disconnected from the river flows, are hydraulically complex (e.g. significant speed, crossroad divergences, presence of obstacles to the flow). A simulation of these flows can be realized with a pseudo 2D modeling, STREAM (software developed by Egis Eau, 1996), which can be implemented in real time because of the rather short computing time required. This modeling approach is based on a finite element resolution of the flow (Figure 3.4). 


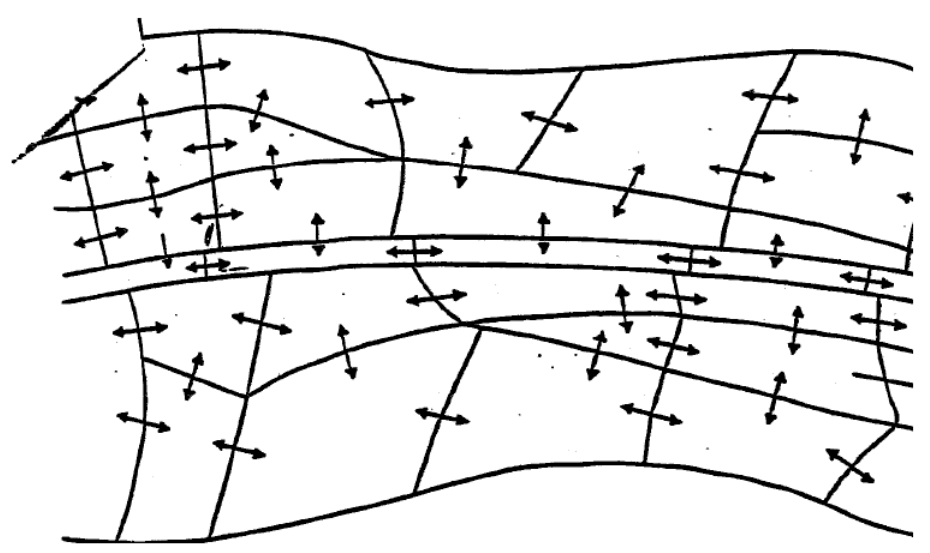

Figure 3.4 Concept of the pseudo-2D hydraulics STREAM software.

However, to gain even more time, it was decided to create a series of various scenarios based on the results of the pseudo 2D model that was developed for each of the downstream rivers.

As a consequence, SDAC is based on the identification in real time of the most probable flood risk scenario based on a series of preset scenarios that were already elaborated. The selection criteria for the scenario based on the hydrological observations and forecasts are the flows at the principal points of forecast, associated with a warning level specified in the security plan of the Conseil Général. For the various forecasting times, precise flooding maps are associated with each scenario in order to represent observed and probable flood hazard and risk in the areas (Figure 3.5). These maps were developed by CALYPSEAU, a GIS tool (software developed by Egis Eau, 1998) that uses the STREAM model results and the DTM data (topographic information).

Depending on the river structures, various number of scenarios are possible for each four basins. Each scenario gives the water level ranges in the flooding zones and are directly related to actions procedures (e.g. road closure, public building alarms).

\subsubsection{Implementation of the Security Plan}

The various warning levels of the system are as follows:

1. Vigilance of the staff; 


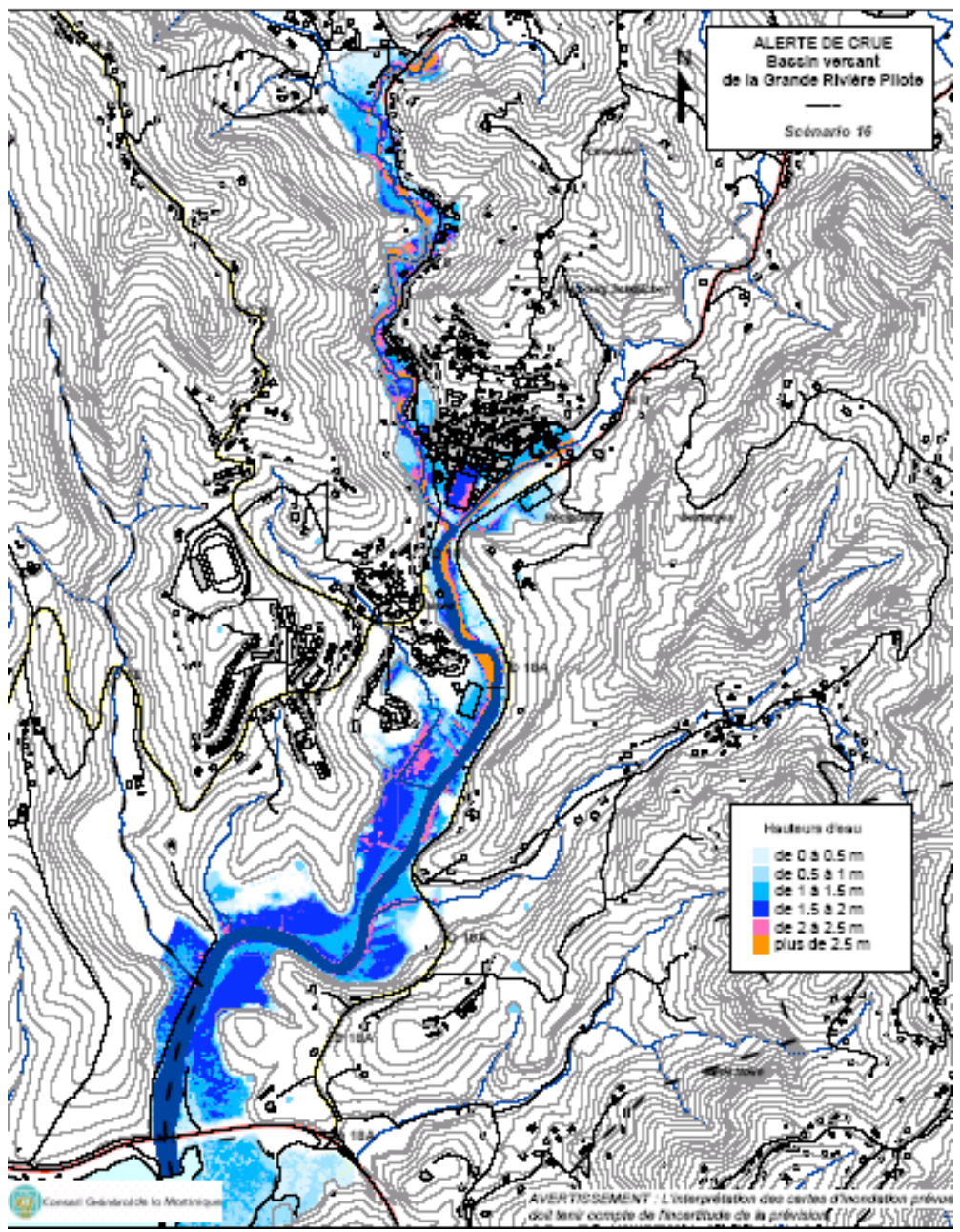

Figure 3.5 Example of a scenario for the Grande Rivière basin.

2. Moderate overflows of the storm network, located flooding;

3. Beginning of the river overflows; and

4. Generalized and serious floods with significant human risks.

The changes of the warning level are proposed by the system. SDAC allows he management of phone calls and email emission related to the actions of the security plan according to the warning level. The phone calls are managed on 
the basis of phone call scenarios. The lists can be filtered according to the current date (weekend or work week, holidays) and time (opening schedules). In addition, a validation of warning message being well received is given by the system.

To inform the population, some operational actions are also based on he system results:

- Visual signage on the roads (Figure 3.6); and

- Barriers in dangerous areas.

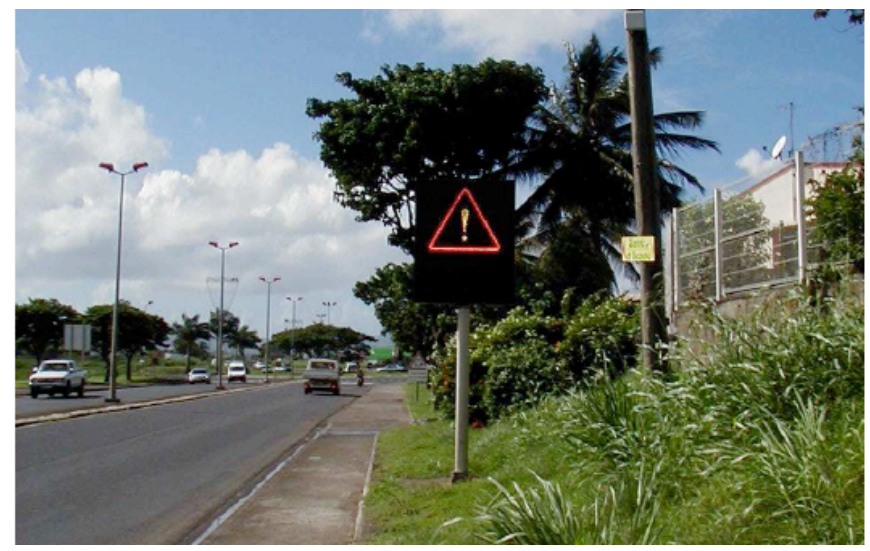

Figure 3.6 Road visual signal to inform the population.

\subsubsection{Web Site}

Another very important communication tool is the the Conseil Général web site that makes all system information available in real time:

- Observed data (rainfall and water level of the rivers);

- $\quad$ Predicted date, hour and location of the warning; and

- $\quad$ Predicted flooding maps (password needed).

On the web site, the images of the video cameras placed on vulnerable sectors are also available in real time.

\subsection{Perspectives of the System}

Based on the context evolution and the progress of informatics capabilities, the following perspective directions are considered for the evolution of the system: 


\section{Radar Data}

Implementation and use of the radar data produced by Météo France. The radar in Martinique is in the calibration phase and should be operational in 2009. The observed and predicted rainfall quantities will be then implemented and used by SDAC to enhance the rainfall information and therefore the system precision (real time warning systems using such data already exist in France).

\section{Model Adaptation}

For a more detailed representation of the sea level constraints, the model will be adapted based on data collected in real time by sea level sensors that will be installed in 2009. This adaptation could lead to interesting modifications of the hydrological model to integrate in real time the downstream constraints of the flows. Three sensors will be installed in the different seas of the island to represent all local conditions.

The growing technological progress associated with the experience feedbacks obtained in practice from the various operational system will contribute to extend the development and success of such real time flood warning systems.

\section{References}

Chocat B., "Encyclopédie de l'hydrologie urbaine et de l'assainissement, Lavoisier", Paris, 1124 pages (1997).

Dumay H, Raymond M., “ESPADA : Un outil pour la gestion des crues urbaine”, Conférence Novatech Lyon (2001).

Editjano et Michel, C., "Un modèle pluie-débit journalier à trois paramètres", La Houille Blanche, 2, 113-121 (1989).

Egis Eau, "STREAM , manuel utilisateur" (1996).

Egis Eau, "Calypseau, manuel utilisateur" (1998).

Perrin C., "Vers une amélioration d'un modèle global pluie-débit au travers d'une approche comparative", Thèse INP CEMAGREF (2000). 